Article

\title{
Stem Formation in French Verbs: Structure, Rules, and Allomorphy
}

\author{
Gustavo L. Estivalet ${ }^{1,2, *}$ and Fanny Meunier 1,2,3 \\ 1 Université Claude Bernard Lyon 1 (UCBL), Villeurbanne 69622, France; fanny.meunier@unice.fr \\ 2 Laboratoire sur le Langage, le Cerveau et la Cognition (L2C2, CNRS UMR5304), Bron 69675, France \\ 3 Laboratoire Bases, Corpus, Langage (BCL, CNRS UMR7320), Nice 06357, France \\ * Correspondence: gustavo.estivalet@isc.cnrs.fr; Tel.: +33-651-231-584
}

Academic Editor: Usha Lakshmanan

Received: 11 July 2016; Accepted: 15 November 2016; Published: 9 December 2016

\begin{abstract}
Stem processing is an essential phase in word recognition. Most modern Romance languages, such as Catalan, Italian, Portuguese, Romanian, and Spanish, have three theme vowels that define verbal classes and stem formation. However, French verbal classes are not traditionally described in terms of theme vowels. In this work, stem formation from theme vowel and allomorphic processes was investigated in French verbs. Our aim was to define the verbal stem formation structure processed during mental lexicon access in French. We conducted a cross-modal experiment and a masked priming experiment on different French stem formation processes from the first and third classes. We compared morphology-related priming effects to full priming obtained through identity priming, as well as to no priming obtained through a control condition. Stems from the first and third classes with a theme vowel presented full priming, whereas stems from the third class with allomorphy presented partial priming in both experiments. Our results suggest root-based stem formation for French. Verbs are recognized through word decomposition into stem and inflectional suffixes, and stem processing is based on root, theme vowel, and allomorphic processes. These results support a single-mechanism model with full decomposition and pre-lexical access defined by morphological rules.
\end{abstract}

Keywords: stem; theme vowel; morphology; inflection; allomorphy; rules; structure; processing; representation; priming

\section{Introduction}

Morphology processing has received considerable attention in psycho-, neuro-, and linguistic research over the last four decades due to the strong symbolic manipulation assumptions that this level underlines [1,2]. The morphological level in word recognition is now better understood, but challenges in language idiosyncrasies and cross-linguistic comparisons remain. In this work, we investigated stem formation defined by theme vowel and allomorphic processes in French verbs. We explored the stem structure and morphological processing in verbal inflection through two priming experiments, one cross-modal and another masked, to better understand stem lexical access during word recognition. The following questions guided our investigation: (a) How are stems from different micro-classes based on different types of stem formation processed? (b) Is the identification of different French verbal forms explained by single- or dual-mechanism models? (c) Are verbal forms pre- or post-lexically decomposed for lexical access?

\subsection{Stems and Theme Vowel}

Diachronically, Romance languages, such as Catalan, Italian, Portuguese, Romanian, and Spanish, inherited their verbal system from Latin, where we observe on the right side a tense node containing the 
tense (T) and agreement (Agr) inflectional suffixes, and on the left side a stem (v) formed by the root $(\sqrt{ })$ with semantic content and a theme vowel (Th) with a functional class distribution, yielding the general verbal hierarchical structure $\left[\left[[\mathrm{parl}]_{\sqrt{ }}[\mathrm{e}]_{\mathrm{Th}}\right]_{\mathrm{V}}\left[[\mathrm{r}]_{\mathrm{T}}[\mathrm{ont}]_{\mathrm{Agr}}\right]_{\mathrm{T}}\right]_{\mathrm{TP}}$ parleront 'they will speak' $[3,4]$. Although the suffixal system is extremely regular and paradigmatic, stem formation presents specific rules and allomorphy, which are consistently affected by the Th and inflectional suffixes [5]. Synchronically, Romance languages reduced the four Latin Th to three (i.e., ' $a$ ', ' $e$ ', and 'i'), as shown in Table 1. The Th is an empty morph without semantic content but with an exclusive functional role in verbal class distribution [6]. However, the French verbal system presents many singularities in stem formation and is not traditionally described in terms of Th [7], but see [3].

Table 1. Infinitive, stem, and Th verbal classes in Romance languages.

\begin{tabular}{ccccc}
\hline Language & $\overline{\mathbf{a}}$ & $\overline{\mathbf{e}}$ & $\overline{\mathbf{e}}$ & $\overline{\mathbf{1}}$ \\
\hline Latin & amāre & prendĕre & vidēre & audīre \\
Italian & amare & prendere & vedere & udire \\
Spanish & amar & prender & ver & oír \\
Portuguese & amar & prender & ver & ouvir \\
Catalan & amar & prendre & veure & sentir \\
French & aimer & prendre & voir & oü̈r \\
Gloss (English) & 'to love' & 'to take' & 'to see' & 'to hear' \\
\hline
\end{tabular}

French is traditionally described as having three verbal classes: the first class with the [-er] ending is fully regular, is productive for new verbs (e.g., googler 'to google'), and includes more than 8500 verbs [8]. The second class with the [-ir] ending with allomorphy in [-iss-] is fully regular, is not productive, and comprises approximately 250 verbs [9]. The third class presents many micro-classes with specific stem formation processes, is not productive, and has approximately 350 verbs [7].

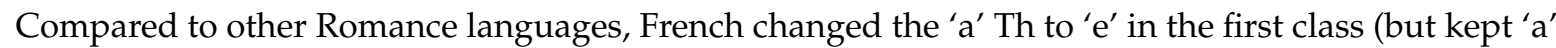
in obsolete tenses, such as in the indicative simple past and subjunctive imperfect past); in the second class, French defined the regular [-ir] ending, which was irregular verbs from the fourth class in Latin and third class in other Romance languages; and in the third class, French suppressed the short ' $\mathrm{e}^{\prime}$ Latin Th, establishing verbs without a Th, changed the long ' $\overline{\mathrm{e}}$ ' Th to 'oi'; and developed many endings as a function of the ' $\mathrm{i}$ ' Th [3].

In the present study, we tested different verbal micro-classes in French to examine whether different types of processing, as postulated by dual-mechanism models, are needed to handle their identification. Indeed, even if the third class presents many different micro-classes (more than 25, see [7]), from a cognitive perspective, it could also be seen as a regular domain driven by combinatorial and allomorphic morphological rules for lexical access and word recognition [10].

\subsection{Inflectional Processing}

Three families of morphological processing models have emerged since the 1970s: symbolic manipulation models, associative activation models, and dual-mechanism models. The first type argues that the mental lexicon contains morphological representations that are activated in word (de)composition, such as the Obligatory Decomposition model [11] and the Single Route model [12]. The second type advocates that the mental lexicon is formed by associative whole word representations [13]. In contrast, Parallel Distributed Processing models compute different weights in the overlap of orthography, phonology, and semantics in hidden units [14]. Alternatively, the amorphous Naïve Discriminative Leaning model predicts no activation of word structure in a direct form-to-meaning computation [15].

Dual-mechanism models propose two routes for word recognition, a direct whole word route and another route operating through morphological decomposition; for example, the Augmented Addressed Morphology (AAM) model dissociates known and unknown words [16], the Parallel 
Dual-Route model asserts a race between both routes [17], and the Words and Rules (W\&R) model differentiates regular and irregular words [18]. Alternatively, the Minimalist Morphology (MM) model proposes a route where irregular words are represented as sub-lexical entries that contain variables [19].

According to Marantz [20] (p. 906), "the separationist understanding of morphemes allows for a complete integration of morphology with the syntax (the 'grammar' in everyday language) such that the internal structure of words finds analysis within the same syntactic architecture and subject to the same syntactic principles as the internal structure of phrases and sentences." However, the morphological hierarchical structure of words has rarely been considered in psycho- and neurolinguistic models of word processing and recognition, although it might have a role in word recognition. This implies that while a simple insertion rule such as lire/lisons 'to read/we read' may demand few resources, a complex substitution rule such as joindre/joignons 'to join/we join' may demand greater resources, impacting the participant's behavior.

Recent findings in English verbal inflection have shown that the morphological structure of words contributes to the form-based decomposition. It seems that the transitional probability from stem to (pseudo)affix modulates early behavioral and neurological components [12,21,22]. Recent work in the English irregular past tense demonstrated that form-based subregularities can be quantified and offer an optimal predictor for morphological processing [23,24]. Fruchter et al. [25] showed that the phonological rules relating irregular forms are a reliable predictor for the morphological decomposition and word recognition. Also, Yang [26] showed that more than the transitional probabilities, the acquisition of the English past tense can be realistically explained when constrained by the phonological and morphological structures. These studies provide evidence for a single-mechanism account in morphological processing exploring form-based and transitional probabilities [20].

Existing Romance language studies on the processing of different verbal classes have yielded contradictory results. Domínguez et al. [27] propose that Spanish verbs from the first class are fully combinatorial whereas verbs from the second and third classes are lexically represented, according to the AAM model, but see [4,28]. A similar pattern of results was observed in Catalan [29], but see [5]. Veríssimo and Clahsen [30] argue that in Portuguese, although first class verbs are fully decomposed using a root-based mechanism, morphophonological first class verbs (e.g., afogar/afogo 'to drown/I drown') and third class verbs are partially decomposed, having different stem representations in the mental lexicon, according to the MM model, but see [31].

Italian presents more controversial results: Caramazza et al. [16] argue in favor of the AAM model, whereas Say and Clahsen [32] propose that regular first class verbs are accessed through the combinatorial route and irregular second and third class verbs are accessed through the whole word route, according to the W\&R model. In contrast, Orsolini and Marslen-Wilson [33] show that priming effects in regular and irregular verbs from the three classes do not differ, suggesting a single-mechanism model with decomposition.

In French, Meunier and Marslen-Wilson [34] observe that different verb types, i.e., fully regular (e.g., aimons/aimer 'we love/to love'), morphophonological (e.g., jettes/jeter 'you throw/to throw'), sub-regular (e.g., peignent/peindre 'they paint/to paint'), and idiosyncratic verbs (e.g., vont/aller 'they go/to go'), may be decomposed for lexical access, suggesting that word recognition in French is morpheme based. Thus, even if stems present morphophonological or allomorphic processes, the paradigmatic suffixal system seems to trigger the decomposition between the stem and inflectional suffixes in all French verbs [35]. Bonami et al. [9] show the systematic regularity of the second class French verbs, which might indeed be considered fully regular because (a) there are no morphophonological verbs in the second class; (b) there are no phonological/orthographic rules in the second class, such as the $<\mathrm{c} / c ̧>$ and $<\mathrm{g} /$ ge $>$ rules found in the first class (e.g., placer/plaçons 'to place/we place', manger/mangeons 'to eat/we eat'); and (c) in the second class, ' $i$ ' Th was completely incorporated into all second class roots where all forms have been stabilized in either $[\sqrt{ } \mathrm{i}]$ before the boundary and consonant or $[\sqrt{ }$ iss- $]$ before vocalic $(V)$ suffixes (i.e., $[\sqrt{ }$ i $] \rightarrow[\sqrt{ }$ iss- $] /$ _V $)$. 
Nevertheless, even if Romance languages such as Catalan, Italian, Portuguese, and Spanish have a more transparent morphological structure where the root, Th, and inflectional suffixes of $\mathrm{T}$ and Agr can be easily identified in verbal forms, and thus, more full priming would be expected, psycholinguistic studies have found full priming in the first class and partial priming in the second and third classes. The main argument for these results is the default fully regular behavior of the first class stem formation with high productivity when compared to the second and third classes [2].

Therefore, differently from these Romance languages, (a) French verbal classes are not traditionally described in terms of Th [7]; (b) the French first class presents morphophonological irregularities (e.g., jeter/jettes 'to throw/you throw', adorer/adores 'to adore/you adore') [10] and phonological/orthographic irregularities (e.g., placer/plaçons 'to place/we place', manger/mangeons 'to eat/we eat') [8]; the second class is fully regular [9]; and the third class presents many micro-classes with regular and productive allomorphic processes [34]. Also, (c) French presents an iambic prosodic system with the stress always falling on the last pronounced syllable, while the other Romance languages present a trochaic prosodic system with the stress falling on the ultimate, penultimate, or antepenultimate syllable [3], and (d) French shows a large inconsistency between the orthographic and phonetic forms, especially regarding the pronunciation of schwa and inflectional suffixes in verbal forms.

The general picture drawn is that Romance languages, even if structurally close, seem different at the morphological processing level; therefore, cross-linguistic comparisons can provide descriptive information for a better understanding of the morphological processing in word recognition [2].

\subsection{Stem Formation}

We conducted a cross-modal experiment and a masked priming experiment with a visual lexical decision task to investigate how stem formation impacts processing of French verbs. Cross-modal priming elicits conscious processing, resulting in lexical core activation through different modalities; however, it captures semantic and orthographic effects, which are undesired in our investigation [34,36]. In contrast, visual masked priming relies on unconscious and automatic effects, providing evidence for rapid and early processes in word recognition [37]. We used a $52 \mathrm{~ms}$ masked prime presentation in our experiment to track morphological processing. At this duration, orthographic overlap produces inhibition and semantic activation is not measurable; thus, priming facilitation can be interpreted as morphological rather than in terms of orthographic overlap or semantic relatedness [21,38].

We tested four different verb types that present specific stem formation processes (one from the first class and three from the third class) and that are considered higher subdivisions in the verbal classes that assemble individual micro-classes. They represent $92.19 \%$ of the total verbs in French, and the three third class verb types tested represent $84.24 \%$ of the total third class verbs, they are also representative of different stem formation processes. The first verb type is fully regular verbs from the first class in [-er] (e.g., parler/parlons 'to speak/we speak'), the second is regular verbs from the third class in [-ir] (e.g., sentir/sentons 'to feel/we feel'), the third is verbs from the third class in [-ire] with allomorphic insertion (e.g., lire/lisons 'to read/we read'), and the fourth is verbs from the third class in [-indre] with allomorphic substitution (e.g., joindre/joignons 'to join/we join') [3,7,8].

We tested three different priming conditions (i.e., control, identity, and test). The identity priming condition reflects full priming and the unrelated control priming condition reflects no priming; thus, the test priming condition was compared to these two conditions. On the one hand, full priming in the test condition indicates that words are fully decomposed into atomic units and that even the stem is parsed into the root and Th, indicating that stem formation is root-based; on the other hand, no priming in the test condition implies that words are not decomposed, favoring whole word representation. Partial priming may indicate that different, albeit linked, allomorphic stem representations are activated in the prime and target pair [1,22,30,32,38,39].

Our hypothesis is that all French verbs from the different micro-classes are morphologically decomposed for lexical access and word recognition; therefore, the morphemic representations are 
processed in the mental lexicon through hierarchical structures, where the stem is processed by means of morphological and phonological rules [24,25,40]. The alternative hypothesis is that only the first class is default root-based and fully decomposed for lexical access, whereas the other classes are word based or stem based, accessed by whole word or sub-lexical entries [16-19].

\section{Materials and Methods}

\subsection{Experiment 1: Cross-Modal Priming}

\subsubsection{Participants}

A total of 48 adult native speakers of French between the ages of 18 and 29 (mean age 21.2; 25 women) participated in Experiment 1. All participants were right-handed, had normal hearing, had normal or corrected-to-normal vision, and had no history of cognitive and neurological disorders. All participants were undergraduate students at the Université Lumière Lyon 2. Participants did not know the purpose of the study and gave their written consent to participate in the experiment as volunteers. The study was conducted in accordance with the Declaration of Helsinki and the protocol was approved by the ethics committee Comité de Protection des Personnes Sud-Est II (IRB: 00009118).

\subsubsection{Material and Design}

The participants took part in a cross-modal priming experiment with auditory priming and a lexical decision task on visual targets. All words were chosen from the French database Lexique [41]. A total of 84 experimental pairs of verbs in four different verb types were selected, with 21 pairs for each verb type. The four verb types investigated were (a) first class fully regular verbs in [-er]; (b) third class regular verbs in [-ir]; (c) third class allomorphic insertion verbs in [-ire]; and (d) third class allomorphic substitution verbs in [-indre].

We manipulated three different priming conditions: (1) control (e.g., aimer/parlons 'to love/we speak'); (2) identity (e.g., parlons/parlons 'we speak/we speak'); and (3) test (e.g., parler/parlons 'to speak/we speak'). The experimental targets and identity priming condition were French verbs inflected in the indicative present tense and first person plural agreement formed by the root and the agreement suffix (i.e., $\left[\left[[\alpha]_{\sqrt{ }}\right]_{\mathrm{V}}\left[[\text { ons }]_{\mathrm{Agr}}\right]_{\mathrm{T}}\right]_{\mathrm{TP}}$, as $\alpha$ being any root); these forms were chosen because they have no Th. The control priming condition was a verb unrelated to the target but from the same verb type in the infinitive form. The test priming condition was the same verb as the target but in the morphology-related infinitive form, which presents the Th. Examples of all experimental conditions are shown in Table 2.

Table 2. Examples of experimental stimuli by verb types and priming conditions investigated in Experiments 1 and 2.

\begin{tabular}{llcccc}
\hline & Verb Type & Control & Test & Identity & Target \\
\hline (a) & First class [-er] & aimer & parler & parlons & PARLONS \\
(b) & Third class [-ir] & dormir & sentir & sentons & SENTONS \\
(c) & Third class [-ire] & écrire & lire & lisons & LISONS \\
(d) & Third class [-indre] & feindre & joindre & joignons & JOIGNONS \\
\hline
\end{tabular}

All experimental words were matched by orthographic lemma frequency, surface frequency, number of letters, number of phonemes, number of syllables, and the orthographic Levenshtein distance from the 20 closest words (OLD20) [42], as shown in Appendix A.

A set of 196 filler pairs was added to the 84 experimental items, resulting in an experiment with a total of 280 stimuli, 30\% of which were experimental pairs. In these 196 filler pairs, there were 84 phonologically related word-pseudoword pairs and 56 unrelated word-pseudoword pairs, producing a total of 140 pairs with a pseudoword target for the non-existent word response. 
Another 56 unrelated word-word pairs were added to the experiment, producing a total of 140 pairs with a real word in the target, accounting for $50 \%$ of the pseudoword targets and $50 \%$ of the real word targets, as well as 50\% of related pairs and $50 \%$ of unrelated pairs. The pseudowords were constructed by changing one or two letter positions using the toolbox available in the French database Lexique [41].

Three different lists were constructed to counterbalance each target with the different priming conditions in a pseudorandom order using the Mix software [43]. All words used in Experiment 1 were recorded by a 22-year-old female native speaker of French.

\subsubsection{Procedure}

The participants were tested individually in a quiet room in the Université Lumière Lyon 2. We used E-Prime 2.0 Professional (Psychology Software Tools, Inc., Sharpsburg, PA, USA, 2012) for experimental construction, stimuli presentation, and data collection. Each trial followed this sequence: first, a fixation point was displayed on the center of the screen for $500 \mathrm{~ms}$; second, an auditory prime was played; and third, immediately after the priming offset, the visual target was displayed on the center of a 15" LCD screen in uppercase 20 point Courier New font in white letters against a black background. The measurement of reaction time (RT) started with the onset of the target presentation, which remained on the screen for $2000 \mathrm{~ms}$ or until the participant's response. After the target disappeared, there was an inter-stimuli blank screen for $500 \mathrm{~ms}$ and the next trial started with the presentation of the fixation point. The participants were asked to perform a lexical decision task on visual targets as quickly and accurately as possible using both hands on a computer keyboard, where the right hand over the 'green' button corresponded to real words and the left hand over the 'red' button corresponded to pseudowords. The entire experiment lasted approximately 24 min.

\subsubsection{Results of Experiment 1}

Only the experimental targets were analyzed. To avoid extreme fast and slow responses, RTs below $300 \mathrm{~ms}$ and above $1800 \mathrm{~ms}$ were removed from the data (0.84\%). Two targets (i.e., CEIGNONS 'we surround' and DEPARTONS 'we depart') had error rates higher than 50\% and were discarded (2.33\%); incorrect responses were removed for the RT analysis (6.25\%). In total, $9.20 \%$ of the experimental stimuli were removed. The overall RT means, standard deviations (SDs), priming differences, significant differences, and error rates are shown in Table 3.

Table 3. Experiment 1: Reaction time (RT) means, standard deviations (SDs) between parentheses, priming differences, significant differences, and error rates by verb type and priming condition. C-T represents control minus test and T-I represents test minus identity.

\begin{tabular}{llcccccc}
\hline & Verb Type & Control & Test & Identity & C-T & T-I & Error (\%) \\
\hline (a) & First class [-er] & $723(211)$ & $637(168)$ & $624(173)$ & $86^{* * *}$ & 13 & 0.85 \\
(b) & Third class [-ir] & $752(202)$ & $659(190)$ & $652(201)$ & $93^{* * *}$ & 7 & 2.25 \\
(c) & Third class [-ire] & $701(192)$ & $645(178)$ & $621(178)$ & $56^{* * *}$ & $24^{* * *}$ & 1.10 \\
(d) & Third class [-indre] & $778(249)$ & $711(209)$ & $676(216)$ & $67^{* * *}$ & $35^{* * *}$ & 2.05 \\
\hline
\end{tabular}

${ }^{*} p<0.05,{ }^{* *} p<0.01,{ }^{* * *} p<0.001$.

RTs were normalized (i.e., $1 / \mathrm{RT}^{*}-1000$, where ${ }^{* \prime}$ means multiplied) and analyzed by means of a mixed-effects model [44], with the transformed RTs as the dependent variable, participants and targets as random variables, and verb type and priming condition as fixed-effect variables. All analyses were performed with R software version 3.1.2 (R Foundation for Statistical Computing, Vienna, Austria, 2014), including lme4, lmerTest, and car packages.

The main results through an analysis of variance (ANOVA) of type III with Satterthwaite approximation for degrees of freedom show a significant effect of verb type $(F(3,77)=4.983, p<0.01)$ and a significant effect of priming condition $(F(2,3529)=165.804, p<0.001)$, but no significant 
interaction between these two variables $(F(6,3529)=1.478, p=0.182)$. Following our hypothesis, we analyzed the planned comparisons of the priming effects by verb type: (a) first class verbs in [-er] present a significant difference between the control and test conditions $(t(3526)=7.284, p<0.001)$, and no difference between the test and identity conditions $(t(3525)=-1.193, p=0.128)$, indicating that the targets are fully primed; (b) third class verbs in [-ir] also show a significant difference between the control and test conditions $(t(3539)=8.068, p<0.001)$, and no difference between the test and identity conditions $(t(3526)=-1.131, p=0.258)$, suggesting again that the targets are fully primed. In contrast, $(c)$ third class verbs in [-ire] present a significant difference between the control and test conditions $(t(3529)=5.622, p<0.001)$, and a significant difference between the test and identity conditions $(t(3526)=-3.615, p<0.001)$, suggesting that the test condition behaves differently from the control and identity conditions, reaching partial priming. Similarly, (d) third class verbs in [-indre] show a significant difference between the control and test conditions $(t(3530)=4.466, p<0.001)$, and a significant difference between the test and identity conditions $(t(3528)=-3.539, p<0.001)$, also suggesting partial priming.

The error rates for the priming conditions were: control $3.71 \%$, identity $1.36 \%$, and test $1.18 \%$. Error rates were analyzed by means of a generalized mixed-effects model [44], with the logit accuracy as the dependent variable, participants and targets as random variables, verb type and priming condition as fixed-effect variables, and the binomial family specified in the model. The analysis of deviance of type II Wald chi-square test shows a significant effect of verb type $\left(\chi^{2}(3, \mathrm{~N}=48)=8.174, p<0.05\right)$ and a significant effect of priming condition $\left(\chi^{2}(2, \mathrm{~N}=48)=81.533, p<0.001\right)$, but no significant interaction between these two variables $\left(\chi^{2}(6, \mathrm{~N}=48)=10.495, p=0.105\right)$.

\subsubsection{Discussion of Experiment 1}

Overall, we observed an effect of morphology-related priming in RTs and error rates. More specifically, we found full priming in the two verb types in which the stem is formed by the combination of root and Th: (a) first class fully regular verbs in [-er] and (b) third class regular verbs in [-ir]. We found partial priming in the two other verb types in which the stem is formed by allomorphic processes: (c) third class allomorphic insertion verbs in [-ire] and (d) third class allomorphic substitution verbs in [-indre].

The full priming effect reveals similarity between the morphology-related and identity priming conditions, thus suggesting the same facilitation between the identity priming stem without the Th and the test priming stem with the Th. Associated with significant differences between morphology-related test and control priming conditions, this result suggests full decomposition of the word and activation of the same morphemes in the prime and target stimuli [1]. Therefore, it seems that the first class fully regular verbs in [-er] and the third class regular verbs in [-ir] were fully decomposed for lexical access and that their morphemic constituents were activated, including the root, because the prime and the target have different stems [30,32].

In contrast, the partial priming results in the third class insertion verbs in [-ire] and the third class substitution verbs in [-indre] suggest different, albeit linked, stem representations activated during the prime and the target stimuli (e.g., [-ire]: [li]re/[lis]ons 'to read/we read', [-indre]: [joind]re/[joign]ons 'to join/we join') [36]. Alternatively, these results can be explained in the light of stem allomorphic rules; in the former, there is a linking consonant insertion into the stem, and in the latter, there is a morphemic substitution in the stem for the merge with the inflectional suffixes [5]. We note that these different stem formation processes seem to be triggered by a formal morphophonological rearrangement in the stem, which is merged with the regular and systematic inflectional suffixes [35]. Therefore, these allomorphic rules might be considered as form-based relations between the inflected forms, especially regarding the transitional probabilities between the stem and inflectional suffixes in the morphological structure, considering the phonological constraints [24,25].

These results are different from those obtained for Catalan [29], Italian [32], Portuguese [30], and Spanish [27], where the results showed full priming only in the first class but partial priming in 
the other classes, but see [33]. Considering the major concerns in cross-modal priming in relation to orthographic, phonological, and semantic effects, we conducted a masked priming experiment with the same linguistic material [37,38].

\subsection{Experiment 2: Masked Priming}

\subsubsection{Participants}

A total of 48 adult native speakers of French between the ages of 18 and 31 (mean age: 22.8; 26 women) participated in Experiment 2; no participants took part in both Experiments 1 and 2. The participants had the same characteristics as described in Experiment 1. Participants did not know the purpose of the study and gave their written consent to participate in the experiment as volunteers. The study was conducted in accordance with the Declaration of Helsinki and the protocol was approved by the ethics committee Comité de Protection des Personnes Sud-Est II (IRB: 00009118).

\subsubsection{Material and Design}

The participants performed a masked priming experiment with a lexical decision task on visual modality using the same material from Experiment 1; additionally, we included a set of stimuli (e) control [orth/sem] (i.e., orthographic and semantic) to control any orthographic and semantic priming effects $[34,38]$. The (e) control [orth/sem] set of stimuli consisted of 21 pairs of words where the targets had the same characteristics as all the other targets. We then manipulated the following three particular priming conditions: (1) control (e.g., réfugier/admirons 'to refuge/we admire'); (2) orthographic (e.g., administrer/admirons 'to administer/we admire'); and (3) semantic (e.g., apprécier/admirons 'to appreciate/we admire'). The control priming condition was a completely different verb, the orthographic priming condition was a verb that was only orthographically related to the target, and the semantic priming condition was a different verb which was only semantically related to the target. The (e) control [orth/sem] set of stimuli was controlled and matched according to the same lexical characteristics as the other verb types, as shown in Appendix B. The complete list of experimental stimuli is shown in Appendix C.

\subsubsection{Procedure}

The participants were tested individually in a quiet room in the Université Lumière Lyon 2. We used the same general procedure as described in Experiment 1. However, in Experiment 2, the primes were presented visually in lowercase for $52 \mathrm{~ms}$ and were preceded by a mask of hash marks for $500 \mathrm{~ms}$. Therefore, each trial followed this sequence: first, a fixation point was displayed on the center of the screen for $500 \mathrm{~ms}$; second, a visual mask with 10 hash marks (largest word) was displayed on the center of the screen for $500 \mathrm{~ms}$; third, immediately after the mask offset, the visual prime was displayed in lowercase for $52 \mathrm{~ms}$; and, fourth, immediately after the prime offset, the visual target was displayed on the center of the screen in uppercase for $2000 \mathrm{~ms}$ or until the participant's response. The entire experiment lasted approximately $20 \mathrm{~min}$.

\subsubsection{Results of Experiment 2}

Only the experimental targets were analyzed. RTs below $300 \mathrm{~ms}$ and above $1800 \mathrm{~ms}$ were removed from the data to avoid extremely fast and slow responses $(0.56 \%)$; one target (i.e., CEIGNONS 'we surround') had an error rate higher than $50 \%$ and was discarded $(0.96 \%)$; incorrect responses were removed for the RT analysis (7.29\%). In total, $8.69 \%$ of the experimental stimuli were removed. The overall RT means, SDs, priming differences, significant differences, and error rates are shown in Table 4 . 
Table 4. Experiment 2: RT means, SDs between parentheses, priming differences, significant differences, and error rates by verb type and priming condition. C-T represents control minus test and T-I represents test minus identity.

\begin{tabular}{llcccccc}
\hline & Verb Type & Control & Test & Identity & C-T & T-I & Error (\%) \\
\hline (a) & First class [-er] & $698(177)$ & $671(180)$ & $665(173)$ & $27^{*}$ & 6 & 0.76 \\
(b) & Third class [-ir] & $740(223)$ & $683(197)$ & $691(216)$ & $57^{* * *}$ & -8 & 2.22 \\
(c) & Third class [-ire] & $686(177)$ & $664(166)$ & $646(200)$ & $22^{*}$ & $18^{*}$ & 0.77 \\
(d) & Third class [-indre] & $810(255)$ & $742(236)$ & $687(212)$ & $68 * *$ & $55^{* * *}$ & 1.97 \\
(e) & Control [orth/sem] & $707(202)$ & $701(184)^{\text {a }}$ & $705(209)$ b & 6 & -4 & 1.57 \\
\hline${ }^{*} p<0.05{ }^{* * *} p<0.01,{ }^{* * *} p<0.001{ }^{\text {a }}$ The test priming condition must be replaced by the semantic priming \\
condition; ${ }^{\text {b }}$ The identity priming condition must be replaced by the orthographic priming condition.
\end{tabular}

The analyses were performed as in Experiment 1. The ANOVA in the RT mixed-effects model shows a significant effect of verb type $(F(4,97)=3.108, p<0.05)$, a significant effect of priming condition $(F(2,4443)=51.054, p<0.001)$, and a significant interaction between these two variables $(F(8,4443)=4.929, p<0.001)$. Proceeding to the planned comparisons, (a) first class verbs in [-er] present a significant difference between the control and test conditions $(t(4443)=2.286, p<0.05)$, and no difference between the test and identity conditions $(t(4442)=-1.191, p=0.234)$, indicating that the targets are fully primed. The same holds for (b) third class verbs in [-ir], a significant difference between the control and test conditions $(t(4442)=5.112, p<0.001)$, and no difference between the test and identity conditions $(t(4446)=0.118, p=0.906)$, indicating that the targets from the first and third classes are fully primed. In contrast, (c) third class verbs in [-ire] present a significant difference between the control and test conditions $(t(4444)=2.204, p<0.05)$, and a significant difference between the test and identity conditions $(t(4443)=-1.971, p<0.05)$, suggesting that the test condition behaves differently from the control and identity conditions, reaching partial priming. A similar pattern is observed for (d) third class verbs in [-indre], with a significant difference between the control and test conditions $(t(4443)=4.553, p<0.001)$, and a significant difference between the test and identity conditions $(t(4445)=-4.066, p<0.001)$, also indicating partial priming of the target. Finally, the (e) control [orth/sem] does not present any difference between the control and semantic conditions $(t(4446)=-0.441, p=0.659)$, or between the control and orthographic conditions $(t(4442)=-0.826$, $p=0.409$ ), suggesting that the semantic and orthographic conditions do not facilitate RTs in target recognition in masked priming.

It becomes clear that the interaction between verb type and priming condition is only significant in the masked priming experiment because of the (e) control [orth/sem] results. An alternative mixed-effects model without this (e) control [orth/sem] condition reveals no significant interaction between verb type and priming condition $(F(6,3546)=1.776, p=0.194)$.

The error rates for the priming conditions were: control $2.87 \%$, identity $2.24 \%$, and test $2.18 \%$. The error rates were analyzed as in Experiment 1 . The results show a significant effect of verb type $\left(\chi^{2}(4, \mathrm{~N}=48)=10.459, p<0.05\right)$ and a significant effect of priming condition $\left(\chi^{2}(2, \mathrm{~N}=48)=7.627\right.$, $p<0.05)$, but no significant interaction between these two variables $\left(\chi^{2}(8, \mathrm{~N}=48)=11.092, p=0.196\right)$.

\subsubsection{Discussion of Experiment 2}

The masked priming experiment showed a pattern of results similar to that of the cross-modal one. Overall, a morphology-related priming effect is observed in RTs and error rate analyses. We found full priming for the (a) first class fully regular verbs in [-er] and the (b) third class regular verbs in [-ir], and partial priming for the (c) third class allomorphic insertion verbs in [-ire] and the (d) third class allomorphic substitution verbs in [-indre].

In line with previous masked priming experiments, there was no significant priming effect in the (e) control [orth/sem] set of stimuli. Thus, the results reject any evidence of facilitation between the prime and target mediated by orthographic overlap or semantic relatedness [21,23,37,38]. 


\section{General Discussion}

\subsection{Morphology as a Complex Domain}

Morphological processing has been a challenging domain in psycho-, neuro-, and linguistic research, yielding contradictory results and the development of different theoretical and psycholinguistic models [1,2]. In this work, we investigated the morphological processing of French stem formation through root and Th combinations and allomorphic rules in four different French verb types using two experimental paradigms: cross-modal priming and masked priming. The results in both experiments revealed a full priming effect for verbs from the first and third classes with stems formed by the combination of root and Th: (a) first class fully regular verbs in [-er] and (b) third class regular verbs in [-ir]. In contrast, the results showed a partial priming effect for verbs from the third class with stems formed by allomorphic rules: (c) third class allomorphic insertion verbs in [-ire] and (d) third class allomorphic substitution verbs in [-indre].

These results are in line with those of Meunier and Marslen-Wilson [34], who showed that fully regular, morphophonological, sub-regular, and idiosyncratic French verbs have similar behaviors, and their access should not be based on dual-mechanism models. The present work extended this investigation to specific stem formation processes driven by root and Th combination, allomorphic insertion, and allomorphic substitution rules. In contrast to other Romance languages which have a more transparent morphological structure, but that found full priming only in the first class and partial priming in the other classes [27,29,30,32], postulating dual-mechanism models or stem based representations, our results showed that in the first and third French verbal classes, target stems that do not contain a Th are equally primed by an identity prime and a test prime in which the stem contains a Th [33].

Therefore, we consider our first question: (a) How are stems from different micro-classes based on different types of stem formation processed? Our results showed differences in priming effects depending on stem formation with root and Th combination in the first class verbs in [-er] and the third class verbs in [-ir] on one side, and allomorphic processes in the third class verbs in [-ire] and the third class verbs in [-indre] on the other side. We observed full priming for verbs that have stems formed by a root and Th combination, but the Th is not present when the stem is merged with vocalic inflectional suffixes (e.g., parler/parlons 'to speak/we speak', dormir/dormons 'to sleep/we sleep', [[ $\sqrt{ }][\mathrm{Th}] \mathrm{v}] \rightarrow$ $[[\sqrt{ }] \mathrm{v}] /$ /V). We observed partial priming for verbs that do not have Th but that contain allomorphic stems according to the suffix with which the stem is merged, implying that these verbs may have different but linked stem representations activated in the prime and target or that they have abstract representations processed by morphological rules. For example, the third class allomorphic insertion verbs in [-ire] would have a simple linking consonant insertion into the allomorphic stem that merges with pronounced suffixes (e.g., disons 'we say', écrivons 'we write'; $[\sqrt{ } \mathrm{i}] \rightarrow[\sqrt{ }$ is $\mid \sqrt{ }$ iv $] /$ VV), while the third class allomorphic substitution verbs in [-indre] would have to be computed by a more complex rule [12,45].

These assumptions and results imply that all French inflected verbs composed of different morphemes seem to be decomposed in their morphemic constituents to be accessed; while forms that have a Th can be stripped and can yield full priming, forms that have allomorphic stems do not have exactly the same morphemic representations activated and yield partial priming.

\subsection{Stem, Allomorphy, and Rules}

We then consider our second question: (b) Is the identification of different French verbal forms explained by single- or dual-mechanism models? The full priming effect between the stem primes with Th and targets without Th in verbs from the first class in [-er] and third class in [-ir] (e.g., [[parl]e]r/[parl]ons 'to speak/we speak', [[dorm]i]r/[dorm]ons 'to sleep/we sleep') suggests that the stems containing the Th were fully decomposed into root and Th and that they activated the same morphemic representation, resulting in equal facilitation relative to that observed in the identity priming condition. The allomorphic third class verbs in [-ire] and third class verbs in [-indre] presented 
partial priming, suggesting that irregular French verbs from the third class have different, albeit linked, allomorphic stem representations [6] or abstract root representations driven by allomorphic rules [40].

Therefore, these results do not require postulating a dual-mechanism model with different routes to process Th and allomorphic stem formations. We argue that a single-mechanism model with morphological decomposition for lexical access can handle these results. This single-mechanism model might have atomic morphemic representations in the mental lexicon for all verb types, i.e., [parl]er 'to speak', [dorm]ir 'to sleep', [écri]re 'to write', [joind]re 'to join'; thus, the former two verb types present full decomposition with simple Th stripping for lemma activation. The latter two verb types also present full decomposition, resulting in different atomic allomorphic stems between the prime and target. The partial priming result observed reflects the activation of these different allomorphic stem representations or the computation of allomorphic rules with different degrees of complexity to transform one form into the other for lemma activation $[10,12,33,34]$. This latter computational interpretation is supported by evidence from recent findings in the English irregular past tense which considered the transitional probabilities of form-based subregularities in the morphological processing in visual word recognition [23,25]. These studies have explored the morphological processing from a statistical learning perspective and have shown that more than a pure probabilistic lexical acquisition, morphological structure and phonological constraints might be considered in word recognition and language processing $[24,26]$.

We then review our third question: (c) Are verbal forms pre- or post-lexically decomposed for lexical access? Our results from the masked priming experiment are in line with previous results on the effects of morphology-related priming. The full priming results from the first class fully regular verbs in [-er] and the third class regular verbs in [-ir] can be compared to those of studies that concluded an early full decompositional mechanism for the first class $[27,29,30,32]$ or for regular verbs $[17,18,39]$. These verbs seem to undergo full decomposition that occurs pre-lexically and is used for lexical access and word recognition [1,22,30,32,37-39], presenting the same verbal hierarchical structure and morphological nodes. They are decomposed early into the stem (lexical morpheme) and inflectional suffixes (functional morphemes) for morphosyntactic feature processing, and the stem is decomposed later into the root and Th for semantic feature processing [45]. We note that in French verbal forms that have the stem directly combined with a pronounced agreement suffix, regular stems do not have the Th and irregular stems present an allomorphic form [3]. Thus, the wide consistency between morphemes in the verbal hierarchical structure and the systematic stem formation processes with Th or allomorphic rules ensures the full decomposition of inflected verbs into atomic morphemic representations $[20,35]$.

Concerning the partial priming results in the third class allomorphic insertion verbs in [-ire] and in the third class allomorphic substitution verbs in [-indre], it can be argued that these micro-classes have linked allomorphic stem representations in the mental lexicon [19,30,39]. Alternatively, we suggest that they could have abstract root representations in the mental lexicon that are morphologically computed through allomorphic rules for lexical access and word recognition [12,40]. In the former interpretation, allomorphic stems have different representations in the mental lexicon that are activated according to the morphological context; these representations are linked in a complementary manner where each form is combined only with specific morphs and inflectional suffixes. This stem allomorphic representation hypothesis is in line with the two-level model proposed in Allen and Badecker [36] and further developed in Crepaldi et al. [23], where sensorial stimuli activate lexeme representations at the first level and these lexemes further activate abstract lemma representations at the second level (e.g., Stimulus: joindre/joignons 'to join/we join'; Lexeme: [joind-]/[joign-]; Lemma: JOINDRE).

In the second interpretation, roots are abstractly represented in the mental lexicon, and the morphological and phonological constraints trigger specific allomorphic rules in the roots to rearrange this morpheme to morphological merge between the stem and inflectional suffixes. This second hypothesis is in line with Stockall and Marantz [12], considering abstract root representations in the mental lexicon that are subject to core morphological and phonological rules for lexical access 
(e.g., Stimulus: joindre/joignons 'to join/we join'; Stem: [joind-]/[joign-]; morphological rule: [ل/ind-] $\rightarrow$ [ $\sqrt{\text { ign- }}] /[\ldots \text {... }]_{\text {pronounced, }}$ phonological rule: $/ \sqrt{\varepsilon} \mathrm{d} / \rightarrow / \sqrt{ } \mathrm{n} / /$ V; Lemma: JOINDRE). Thus, form-based subregularities, morphological structure, and phonological constraints in different allomorphic forms may play a role in word recognition and language processing. It is suggested that these characteristics trigger more or less robust morphological decomposition and morphemic activation in the function of statistical computations based on transitional probabilities and phonological constraints [24-26]. Further experiments are needed to determine which interpretation is correct.

Independently of the hypothesis adopted, the results from both experiments support a root-based system for French verbal processing, with the inflected verbs decomposed into stem and inflectional suffixes and the stem decomposed into root and Th, if available, or allomorphic rules for lexical access. Finally, the implication is that because all verbal forms are fully decomposed into atomic units for lexical access, we should consider that the mental lexicon of French can be composed of morphemic representations that are hierarchically structured and processed in a symbolically computational and combinatorial manner $[5,10,12,20,24,26,40,45]$.

\section{Conclusions}

Unlike experimental studies on other Romance languages, we showed that French verbs from the first and third classes can be accounted by a single-mechanism model with morphological processing for lexical access [10-12,33,34]. Our results suggest root-based processing for lexical access and word recognition. We propose that French inflected verbs are first decomposed into the stem and inflectional suffixes and later the stem is then processed at the lexeme level for subsequent lemma activation [36]. Finally, we showed that stem formation is strongly driven by morphological rules and allomorphic processes.

Supplementary Materials: We made all data and materials completely available. Lexical matching information are available in the Appendixs A and B, and the list of all experimental stimuli is available in the Appendix C, in the body of the article. In the Supplementary Materials of the article in the MDPI-Languages, we made available in Table S1: Dataset from Experiment 1-Cross-Modal Priming; in Table S2: Dataset from Experiment 2-Masked Priming, and in Text S3: R script for statistical analyses, in the two experiments. They are available online at http://www.mdpi.com/2226-471X/1/2/13/s1.

Acknowledgments: We thank two MDPI — Languages reviewers for helpful and valuable suggestions on an earlier version of this article. We are also grateful to Harald Clahsen and João Veríssimo for their insightful comments on a previous version of this work. We thank American Journal Experts (AJE) for writing corrections in article (1045-6A55-EBF0-A7E4-C46E). This research was supported by funding from a Ph.D. grant from the National Council of Scientific and Technological Development-CNPq, Brazil (238186/2012-1) to the first author, and by the Centre National de la Recherche Scientifique-CNRS, France (L2C2/UMR5304).

Author Contributions: Both authors G.L.E. and F.M. contributed equally to the development of this study, including the theoretical conception, experimental protocol and design, empirical research, data acquisition and analysis, and article writing.

Conflicts of Interest: The authors declare no conflicts of interest. The funding sponsors had no role in the design of the study; in the collection, analyses or interpretation of data; in the writing of the manuscript; or in the decision to publish the results.

\section{Appendix A}

Table A1. Means of each verb type and priming condition. flemma: lemma frequency, fsurf: surface frequency, letters: number of letters, phon: number of phonemes, syll: number of syllables, hom: number of homographs, and OLD20: Orthographic Levenshtein Distance.

\begin{tabular}{cccccccccc}
\hline & Verb Type & Priming & flemma & fsurf & letters & phon & syll & hom & OLD20 \\
\hline (a) & First class [-er] & Control & 47.98 & 11.29 & 8.14 & 6.19 & 2.86 & 1.05 & 1.86 \\
& & Test & 48.03 & 11.27 & 8.10 & 6.29 & 3.00 & 1.05 & 1.82 \\
& & Target & 48.03 & 0.20 & 9.10 & 6.29 & 3.00 & 1.10 & 2.26 \\
(b) & \multirow{2}{*}{ Third class [-ir] } & Control & 47.59 & 11.08 & 7.52 & 6.57 & 2.67 & 1.00 & 2.26 \\
& & Test & 47.62 & 11.13 & 8.05 & 6.62 & 2.67 & 1.00 & 1.90 \\
& & Target & 47.62 & 0.21 & 9.05 & 5.62 & 2.67 & 1.10 & 2.01 \\
\hline
\end{tabular}


Table A1. Cont.

\begin{tabular}{lccccccccc}
\hline & Verb Type & Priming & flemma & fsurf & letters & phon & syll & hom & OLD20 \\
\hline (c) & Third class [-ire] & Control & 47.51 & 11.57 & 8.33 & 6.43 & 2.29 & 1.00 & 2.25 \\
& & Test & 47.47 & 12.03 & 7.14 & 5.81 & 1.86 & 1.05 & 1.85 \\
& & Target & 47.47 & 0.08 & 9.14 & 6.81 & 2.86 & 1.00 & 2.11 \\
(d) & \multirow{2}{*}{ Third class [-indre] } & Control & 46.86 & 10.48 & 8.19 & 6.24 & 2.00 & 1.00 & 2.22 \\
& & Test & 46.77 & 10.38 & 8.33 & 5.33 & 1.57 & 1.05 & 2.16 \\
& & Target & 46.77 & 0.18 & 9.33 & 5.67 & 2.57 & 1.05 & 2.07 \\
\hline
\end{tabular}

\section{Appendix B}

Table B1. Means of the (e) control [orth/sem] (i.e., orthographic and semantic) verb type by priming condition in Experiment 2 added to the complete material presented in Appendix A.

\begin{tabular}{|c|c|c|c|c|c|c|c|c|c|}
\hline & Verb Type & Priming & flemma & fsurf & letters & phon & syll & hom & OLD20 \\
\hline \multirow[t]{4}{*}{ (e) } & [orth/sem] & Control & 47.03 & 11.46 & 7.90 & 6.19 & 2.43 & 1.10 & 1.98 \\
\hline & & Semantic & 46.30 & 10.71 & 7.90 & 6.24 & 3.00 & 1.00 & 1.96 \\
\hline & & Ortho & 49.75 & 12.49 & 7.86 & 5.86 & 2.67 & 1.05 & 2.11 \\
\hline & & Target & 49.08 & 0.37 & 8.90 & 6.00 & 2.62 & 1.00 & 2.24 \\
\hline
\end{tabular}

\section{Appendix C}

Table C1. List of all the experimental stimuli.

\begin{tabular}{|c|c|c|c|c|c|}
\hline \multicolumn{3}{|c|}{ (a) First class [-er] } & \multicolumn{3}{|c|}{ (b) Third class [-ir] } \\
\hline Target & Test & Control & Target & Test & Control \\
\hline accrochons & accrocher & commander & accueillons & accueillir & frémir \\
\hline alignons & aligner & estimer & bouillons & bouillir & maigrir \\
\hline aventurons & aventurer & identifier & consentons & consentir & embellir \\
\hline consultons & consulter & associer & cueillons & cueillir & pétrir \\
\hline coupons & couper & glisser & défaillons & défaillir & rebondir \\
\hline débutons & débuter & suspecter & démentons & démentir & surenchérir \\
\hline détaillons & détailler & pratiquer & départons & départir & resplendir \\
\hline dictons & dicter & notifier & desservons & desservir & subvertir \\
\hline divisons & diviser & confronter & dévêtons & dévêtir & encourir \\
\hline emportons & emporter & résister & endormons & endormir & choisir \\
\hline facilitons & faciliter & informer & mentons & mentir & subir \\
\hline félicitons & féliciter & contrôler & offrons & offrir & ravir \\
\hline inventons & inventer & souffler & pressentons & pressentir & férir \\
\hline présentons & présenter & chanter & recouvrons & recouvrir & accourir \\
\hline préservons & préserver & indiquer & recueillons & recueillir & désobéir \\
\hline réparons & réparer & exposer & repartons & repartir & maintenir \\
\hline signons & signer & protester & ressentons & ressentir & ouvrir \\
\hline simplifions & simplifier & diluer & revêtons & revêtir & subvenir \\
\hline sollicitons & solliciter & lamenter & rouvrons & rouvrir & enquérir \\
\hline supposons & supposer & attacher & souffrons & souffrir & réfléchir \\
\hline tremblons & trembler & attaquer & vêtons & vêtir & languir \\
\hline
\end{tabular}




\begin{tabular}{|c|c|c|c|c|c|}
\hline \multicolumn{3}{|c|}{ (c) Third class [-ire] } & \multicolumn{3}{|c|}{ (d) Third class [-indre] } \\
\hline Target & Test & Control & Target & Test & Control \\
\hline construisons & construire & battre & astreignons & astreindre & prédire \\
\hline cuisons & cuire & débattre & atteignons & atteindre & permettre \\
\hline décrivons & décrire & interrompre & ceignons & ceindre & éprendre \\
\hline déduisons & déduire & adjoindre & contraignons & contraindre & accroître \\
\hline détruisons & détruire & recevoir & craignons & craindre & transmettre \\
\hline élisons & élire & réentendre & dépeignons & dépeindre & ébattre \\
\hline enduisons & enduire & démettre & déteignons & déteindre & promouvoir \\
\hline induisons & induire & équivaloir & enfreignons & enfreindre & reluire \\
\hline inscrivons & inscrire & commettre & enjoignons & enjoindre & éconduire \\
\hline introduisons & introduire & rasseoir & éteignons & éteindre & dissoudre \\
\hline lisons & lire & conduire & étreignons & étreindre & croître \\
\hline luisons & luire & omettre & feignons & feindre & extraire \\
\hline nuisons & nuire & réapprendre & geignons & geindre & raire \\
\hline prescrivons & prescrire & épandre & joignons & joindre & instruire \\
\hline produisons & produire & disparaître & oignons & oindre & enclore \\
\hline récrivons & récrire & échoir & peignons & peindre & coudre \\
\hline réduisons & réduire & survivre & plaignons & plaindre & convaincre \\
\hline relisons & relire & maudire & rejoignons & rejoindre & écrire \\
\hline suffisons & suffire & pourvoir & repeignons & repeindre & méconnaître \\
\hline traduisons & traduire & séduire & reteignons & reteindre & morfondre \\
\hline transcrivons & transcrire & ensuivre & teignons & teindre & parfaire \\
\hline
\end{tabular}

\begin{tabular}{cccc}
\hline & \multicolumn{2}{c}{ (e) Control [orth/sem] } & \\
\hline Target & Orthographic & Semantic & Control \\
\hline admirons & administrer & apprécier & réfugier \\
causons & causette & engendrer & signaler \\
cèdent & centrer & fêter & liquider \\
célèbrent & celer & abandonner & diriger \\
conduisons & condition & guider & méprendre \\
correspondons & correction & concorder & vaincre \\
couvrons & couver & abriter & croupir \\
découvrons & demeurer & dévoiler & contenir \\
disjoignons & disjoncter & séparer & contredire \\
enlèvent & enlacer & retirer & visiter \\
instruisons & instrument & éduquer & inclure \\
liquidons & liqueur & débarasser & conseiller \\
oyons & oublier & débarquer & reservoir \\
redescendons & redessiner & remarquer & dissocier \\
repèrent & repenser & imiter & rouler \\
reproduisons & reprocher & provenir & décroître \\
ressortons & ressouder & émerger & souvenir \\
saillons & saisir & fasciner & fuir \\
séduisons & serrer & écouter & foutre \\
veillons & veines & somnoler & briquer \\
vendons & venter & marchander & surprendre \\
\hline
\end{tabular}

\section{References}

1. Amenta, S.; Crepaldi, D. Morphological Processing as We Know It: An Analytical Review of Morphological Effects in Visual Word Identification. Front. Psychol. 2012, 3, 232. [CrossRef] [PubMed] 
2. Clahsen, H. Linguistic perspectives on morphological processing. In Advances in the Theory of the Lexicon; Wunderlich, D., Ed.; Mouton de Gruyter: Berlin, Germany, 2006; pp. 355-388.

3. Foley, J. Theoretical Morphology of the French Verb; Benjamins: Amsterdam, The Netherlands, 1979.

4. Arregi, K. How the Spanish verb works. In Presented at LSRL 30, University of Florida, Gainesville, FL, USA, February 2000.

5. Oltra-Massuet, M.I. On the Notion of Theme Vowel: A New Approach to Catalan Verbal Morphology. Master's Thesis, Departement of Linguistics and Philosophy, Massachusetts Institute of Technology (MIT), Cambridge, MA, USA, 1999.

6. Aronoff, M. Morphological stems: What William of Ockham really said. Word Struct. 2012, 5, $28-51$. [CrossRef]

7. Kilani-Schoch, M.; Dressler, W.U. Morphologie Naturelle et Flexion du Verbe Français; Gunter Narr Verlag Tübingen: Tübingen, Germany, 2005.

8. Bescherelle. Bescherelle: La Conjugaison Pour Tous; Hatier: Paris, France, 2006.

9. Bonami, O.; Boyé, G.; Giraudo, H.; Voga, M. Quels verbes sont réguliers en français? In Congrès Mondial de Linguistique Française 2008; Durand, J., Habert, B., Laks, B., Eds.; EDP Sciences: Les Ulis, France, 2008; pp. 1511-1523.

10. Estivalet, G.L.; Meunier, F.E. Decomposability and mental representation of French verbs. Front. Hum. Neurosci. 2015, 9, 4. [CrossRef] [PubMed]

11. Taft, M. Recognition of affixed words and the word frequency effect. Mem. Cogn. 1979, 7, 263-272. [CrossRef]

12. Stockall, L.; Marantz, A. A single route, full decomposition model of morphological complexity: MEG evidence. Ment. Lex. 2006, 1, 85-123. [CrossRef]

13. Manelis, L.; Tharp, D.A. The processing of affixed words. Mem. Cogn. 1977, 5, 690-695. [CrossRef] [PubMed]

14. Rumelhart, D.E.; McClelland, J.L. On learning the past tenses of English verbs. In Parallel Distributed Processing: Explorations in the Microstructures of Cognition; Rumelhart, D.E., McClelland, J.L., Group PDPR, Eds.; The MIT Press: Cambridge, MA, USA, 1986; pp. 216-271.

15. Baayen, R.H.; Milin, P.; Đurđević, D.F.; Hendrix, P.; Marelli, M. An amorphous model for morphological processing in visual comprehension based on naive discriminative learning. Psychol. Rev. 2011, 118, 438-481. [CrossRef] [PubMed]

16. Caramazza, A.; Laudanna, A.; Romani, C. Lexical access and inflectional morphology. Cognition 1988, 28, 297-332. [CrossRef]

17. Baayen, R.H.; Dijkstra, T.; Schreuder, R. Singulars and Plurals in Dutch: Evidence for a Parallel Dual-Route Model. J. Mem. Lang. 1997, 37, 94-117. [CrossRef]

18. Pinker, S. Words and Rules: The Ingredients of Language; Weidenfeld and Nicolson: London, UK, 1999.

19. Wunderlich, D. Minimalist morphology: The role of paradigms. In Yearbook of Morphology 1995; Booij, G., van Marle, J., Eds.; Springer: Dordrecht, The Netherlands, 1996; pp. 93-114.

20. Marantz, A. No escape from morphemes in morphological processing. Lang. Cogn. Process. 2013, 28, 905-916. [CrossRef]

21. Longtin, C.-M.; Meunier, F. Morphological decomposition in early visual word processing. J. Mem. Lang. 2005, 53, 26-41. [CrossRef]

22. Rastle, K.; Davis, M.H. Morphological decomposition based on the analysis of orthography. Lang. Cogn. Process. 2008, 23, 942-971. [CrossRef]

23. Crepaldi, D.; Rastle, K.; Coltheart, M.; Nickels, L. "Fell" primes "fall", but does "bell" prime "ball"? Masked priming with irregularly-inflected primes. J. Mem. Lang. 2010, 63, 83-99. [CrossRef]

24. Albright, A. Islands of Reliability for Regular Morphology: Evidence from Italian. Language (Baltim). Linguist. Soc. Am. 2002, 78, 684-709. [CrossRef]

25. Fruchter, J.; Stockall, L.; Marantz, A. MEG masked priming evidence for form-based decomposition of irregular verbs. Front. Hum. Neurosci. 2013, 7, 798. [CrossRef] [PubMed]

26. Yang, C.D. Universal Grammar, statistics or both? Trends Cogn. Sci. 2004, 8, 451-456. [CrossRef] [PubMed]

27. Domínguez, A.; Cuetos, F.; Segui, J. Morphological processing in word recognition: A review with particular reference to Spanish. Psicológica 2000, 21, 375-401.

28. Bermúdez-Otero, R. The Spanish lexicon stores stems with theme vowels, not roots with inflectional class features. Int. J. Lat. Roman Linguist._Probus 2013, 25, 3-103. 
29. Rodriguez-Fornells, A.; Clahsen, H.; Lleó, C.; Zaake, W.; Münte, T.F. Event-related brain responses to morphological violations in Catalan. Cogn. Brain Res. 2001, 11, 47-58. [CrossRef]

30. Veríssimo, J.; Clahsen, H. Morphological priming by itself: A study of Portuguese conjugations. Cognition 2009, 112, 187-194. [CrossRef] [PubMed]

31. Bassani, I.S.; Lunguinho, M.V. Revisitando a flexão verbal do português à luz da Morfologia Distribuída: Um estudo do presente, pretérito imperfeito e pretérito perfeito do indicativo. Revista Virtual de Estudos da Ling.--Revel 2011, 5, 199-227.

32. Say, T.; Clahsen, H. Words, rules and stems in the Italian mental lexicon. In Storage and Computation in the Language Faculty; Nooteboom, S., Weerman, F., Wijnen, F., Eds.; Kluwer: Dordrecht, The Netherlands, 2002; pp. 93-129.

33. Orsolini, M.; Marslen-Wilson, W. Universals in Morphological Representation: Evidence from Italian. Lang. Cogn. Process. 1997, 12, 1-47. [CrossRef]

34. Meunier, F.; Marslen-Wilson, W. Regularity and irregularity in French verbal inflection. Lang. Cogn. Process. 2004, 19, 561-580. [CrossRef]

35. Fabre, D.; Schoot, L.; Meunier, F. What triggers early decomposition of morphologically complex words? In EuroCogSci07, The European Cognitive Science Conference; Vosniadou, S., Kayser, D., Protopapas, A., Eds.; Lawrence Erlbaum Associates: Delphi, Greece, 2007; pp. 734-739.

36. Allen, M.; Badecker, W. Inflectional Regularity: Probing the Nature of Lexical Representation in a Cross-Modal Priming Task. J. Mem. Lang. 2002, 46, 705-722. [CrossRef]

37. Forster, K.I.; Davis, C. Repetition priming and frequency attenuation in lexical access. J. Exp. Psychol. Learn. Mem. Cogn. 1984, 10, 680-698. [CrossRef]

38. Forster, K.I. The Pros and Cons of Masked Priming. J. Psycholinguist. Res. 1998, 27, 203-233. [CrossRef] [PubMed]

39. Clahsen, H. Lexical entries and rules of language: A multidisciplinary study of German inflection. Behav. Brain Sci. 1999, 22, 991-1013. [CrossRef] [PubMed]

40. Halle, M.; Marantz, A. Distributed morphology and the pieces of inflection. In The View from Building 20: Essays in Linguistics in Honor of Sylvain Bromberger; Hale, K., Keyser, S.J., Eds.; The MIT Press: Cambridge, MA, USA, 1993; pp. 111-176.

41. New, B.; Pallier, C.; Brysbaert, M.; Ferrand, L. Lexique 2: A new French lexical database. Behav. Res. Methods Instrum. Comput. 2004, 36, 516-524. [CrossRef] [PubMed]

42. Yarkoni, T.; Balota, D.; Yap, M. Moving beyond Coltheart's N: A new measure of orthographic similarity. Psychon. Bull. Rev. 2008, 15, 971-979. [CrossRef] [PubMed]

43. van Casteren, M.; Davis, M.H. Mix, a program for pseudorandomization. Behav. Res. Methods 2006, 38, 584-589. [CrossRef] [PubMed]

44. Baayen, R.H. Analyzing Linguistic Data: A Practical Introduction to Statistics; Cambridge University Press: Cambridge, UK, 2008.

45. Embick, D.; Halle, M. On the status of stems in morphological theory. In Procedings of Going Romance 2003; Geerts, T., Jacobs, H., Eds.; John Benjamins: Amsterdam, The Netherlands, 2005; pp. 59-88.

(C) 2016 by the authors; licensee MDPI, Basel, Switzerland. This article is an open access article distributed under the terms and conditions of the Creative Commons Attribution (CC-BY) license (http://creativecommons.org/licenses/by/4.0/). 